\title{
Effects of Carbonation on the Properties of Concrete
}

\author{
Ikumapayi C. M." \\ The Federal University of Technology, Akure, Nigeria \\ Elizade University, Ilara-mokin, Nigeria
}

Adeniji A. A.

Elizade University, Ilara-mokin, Nigeria

Obisesan A. A.

Elizade University, Ilara-mokin, Nigeria

Odeyemi $O$.

Elizade University, Ilara-mokin, Nigeria

Ajayi J. A.

Elizade University, Ilara-mokin, Nigeria

\begin{abstract}
Concrete is one of the reliable, durable, economical and acceptable construction materials among the building and construction stakeholders worldwide. Performance of concrete could be threatened especially reinforced concrete by some processes such as corrosion, sulfate attack among others. Corrosion of reinforcement in reinforced concrete can be induced by carbonation process. Even though carbonation initiates corrosion, it has been gathered that carbonation could still be of immense benefits to building and construction industries if its mechanism of operation is understudied. This research work has therefore investigated the effect of carbonation on some selected mechanical properties of concrete such as compressive strength, flexural strength, water absorption and weight changes. Concrete cubes and beams of M15 grade with $0.5 \%$ water-cement ratio were prepared and subjected to accelerated carbonation. Their compressive strength, flexural strength, water absorption and weight changes were determined in accordance with the relevant standards. The outcomes show that carbonation improves all the mechanical properties investigated. The use of carbonation can be positively explored in reinforced concrete provided there is adequate nominal cover.
\end{abstract}

Keywords: Carbonation; Compressive strength; Flexural strength; Water absorption rate; Weight change.

(ㄷ) (1) CC BY: Creative Commons Attribution License 4.0

\section{Introduction}

Mankind has since many decades ago accepted and has been exploring the use of concrete as one the vital construction materials worldwide [1]. Its acceptability is based on its ability to be moulded into various shapes when in plastic stage and its strength as well as durability when in hardened state. Sustainability and resiliency have also been identified as advantages of concrete over other construction materials Hajek [2]; Qasim [3]; Qasim and Ahmed [4]. These coupled with low maintenance cost, adequate fire resistance and introduction of reinforcement to improve the tensile resistance [5]. All these and many more have made concrete famous among building and construction stakeholders. Concrete consists mainly of cement, fine aggregate, coarse aggregate, and water. Sometimes admixtures could be added depending on the desired properties of the intended concrete [6]. Durability of concrete structures exposed to aggressive environments can be mitigated through various processes and this has become a major concern of structural engineers as well as the built and construction environment as a whole. One of these mitigating processes is corrosion of reinforced concrete [7, 8]. Corrosion causes failure of reinforced concrete structure before the designed service life is accomplished. It has also been reported that corrosion can be initiated by carbonation $[9,10]$. In reinforced steel, carbonation can be defined as the process whereby carbon dioxide diffuses through the pores of the concrete and reacts with concrete hydration products such as calcium hydroxide and calcium silicate hydrates $[11,12]$. Carbonation reduces the $\mathrm{pH}$ of concrete pore solution to a value less than 9 and steel passive oxide film may be destroyed which in turn, accelerates uniform corrosion [11, 12]. The treat from carbonation on the reinforced cement concrete (RCC) has led to corrosion of the reinforcing bars and has resulted into total collapse of residential buildings and commercial buildings [13, 14]. Despite the reported negative impact of carbonation on reinforced concrete, it has been recently discovered that carbonated concrete can also be of good benefit to construction industries in the area of compressive strength improvement [13]. Various researchers have studied the effects of carbonation on compressive strength, permeability, resistance to chloride ion, mechanism of carbonation and physical characteristic of carbonated mortar. Their discoveries show that good things can come out of carbonation process. Therefore, this research aims at bringing into limelight more positive effects of carbonation on concrete and reinforced concrete. Investigation of the effects of carbonation on some selected properties of 
concrete such as compressive strength, flexural strength, weight changes and water absorption of the concrete was carried out. Natural rate of carbonation can be very slow therefore, testing were done by accelerating the process using the atmosphere of relatively high $\mathrm{CO}_{2}$ concentration.

\subsection{Mechanism of Corrosion Induced by Carbonation}

Literature review revealed that calcium hydroxide, $\mathrm{Ca}(\mathrm{OH})_{2}$ is responsible for the high $\mathrm{pH}$ in concrete. When $\mathrm{Ca}(\mathrm{OH})_{2}$ reacts with carbon dioxide $\mathrm{CO}_{2}$, the $\mathrm{pH}$ in the pore solution reduces. This reduction in the $\mathrm{pH}$ destroys the passive film around the steel bar and creates chance for corrosion to take place [14]. The corrosion induced by carbonation can increase the possibility of crack development and decrease the durability of concrete [15]. The pore solution of concrete has a $\mathrm{pH}$ of about 12 to 13 [16] but a full carbonated concrete has a $\mathrm{pH}$. value between 7-8.3 when complete consumption of calcium hydroxide has taken place [14]. The decrease in the value of $\mathrm{pH}$ that calls for an acidic environment. The destruction of the passive films begins when the $\mathrm{pH}$ value is lower than 11.5 [17]. The basic factors governing the process of carbonation are the quantity of pozzolanic material, the humidity conditions, and the duration of exposure [18]. Chi, et al. [19], observed that the process of carbonation reduces the surface porosity of the concrete because the resulting $\mathrm{CaCO}_{3}$ occupies a greater volume than $\mathrm{Ca}(\mathrm{OH})_{2}$. The reaction of carbon dioxide and calcium hydroxide only occurs in solution and so in very dry concrete when the relative humidity $(\mathrm{RH})<40 \% \mathrm{CO}_{2}$ cannot dissolve therefore carbonation will be slow. In saturated concrete where $\mathrm{RH}>$ $90 \%$ the moisture presents a barrier to the penetration of carbon dioxide and again carbonation will be slow. The most favorable condition for the carbonation reaction is when there is sufficient moisture (i.e when RH ranges between 40-90\%) for the reaction but not enough to act as a barrier [20]. In most structures made with good quality concrete, carbonation will take several (or many) years to reach the level of the reinforcement. The process of carbonation are shown in the chemical equation (1).

$$
\mathrm{Ca}(\mathrm{OH})_{2}+\mathrm{CO}_{2} \rightarrow \mathrm{CaCO}_{3}+\mathrm{H}_{2} \mathrm{O}
$$

\section{Materials and Method}

The materials used for this research work are Portland lime cement (PLC), fine aggregate, coarse aggregate, potable water, Carbon dioxide gas $\left(\mathrm{CO}_{2}\right)$, Sodium chloride solution, Phenolphthalein indicator solution, $12 \mathrm{~mm}$ and $8 \mathrm{~mm}$ reinforcement, iron-mould of $150 \times 150 \times 150 \mathrm{~mm}^{3}$ and wooden formwork of $150 \mathrm{~mm} \times 150 \mathrm{~mm} \times$ $700 \mathrm{~mm}$ dimensions among others.

\subsection{Mix Proportions and Materials Testing}

The densities of the PLC, fine aggregate, coarse aggregate, portable water and $\left(\mathrm{CO}_{2}\right)$ were determined and reported. shown in Table 1. Particle size distribution test was carried out on the fine aggregate in accordance with BS 1377-2 [21] and the result is as shown in Figure $1.30 \mathrm{~kg}$ of $\mathrm{CO}_{2}$, a colorless and odorless gas with a density of about $60 \%$ higher than that of dry air was used.

Table-1. Properties of materials used for the research

\begin{tabular}{l|l|l}
\hline Material & Density $\left(\boldsymbol{k g} / \boldsymbol{m}^{\mathbf{3}}\right)$ & Size $(\mathbf{m m})$ \\
\hline Fine aggregate & 1271 & $<4.75$ \\
\hline Coarse aggregate & 1488 & $10-20$ \\
\hline Portland Lime Cement (PLC) & 1346 & \\
\hline Water & 1000 & \\
\hline Carbon dioxide & 1.98 & \\
\hline
\end{tabular}

The mix proportion used during this experiment was M15 of mix ratio 1: 2: 4 (water: fine aggregate: coarse aggregate) by weight. The cement setting time and soundness tests were conducted according to BS EN 196-3 [22]. Particle size distribution test of the fine aggregate used in this research work was conducted in accordance with BS 1377-2 [21]. The slump test was conducted according to [23] on the fresh concrete used to produce the specimens.

\subsection{Determination of Carbonation on Concrete Properties}

Concrete cubes of size $150 \times 150 \times 150 \mathrm{~mm}$ and beams of size $150 \times 150 \times 700 \mathrm{~mm}$ were produced using the mix ratio of 1:2:4 for cement, sand and aggregates respectively. A total number of 50 cubes and 12 beams prepared. These concrete samples were demoulded after 24 hours of casting. They were then cured by immersion in water. After curing, the concrete cubes and beams were placed in the carbonation chamber. The carbonation chamber was connected to $\mathrm{CO}_{2}$ gas cylinder through a pipe as indicated in Figure1. Carbonation chamber was fabricated in such a way that it was air tight with a top cover that was removable for placing and taking out the concrete specimens. A perforated platform was fabricated at height of $0.06 \mathrm{~m}$ from bottom of the chamber to avoid direct contact between the concrete specimens and salt solution. A saturated laboratory reagent sodium chloride salt solution was kept below this perforated platform in the chamber to maintain the required relative humidity [11]. Control concrete cubes and beams were not put in the carbonated chamber but left in the open to serve as the control specimens. The properties of concrete were determined for carbonated and non-carbonated at 7 days, 21 days and 28 days. All the experiment was carried out in Elizade university workshop, Ilara-mokin Ondo state, Nigeria. 
Figure-1. Accelerated carbonation chamber and the concrete samples

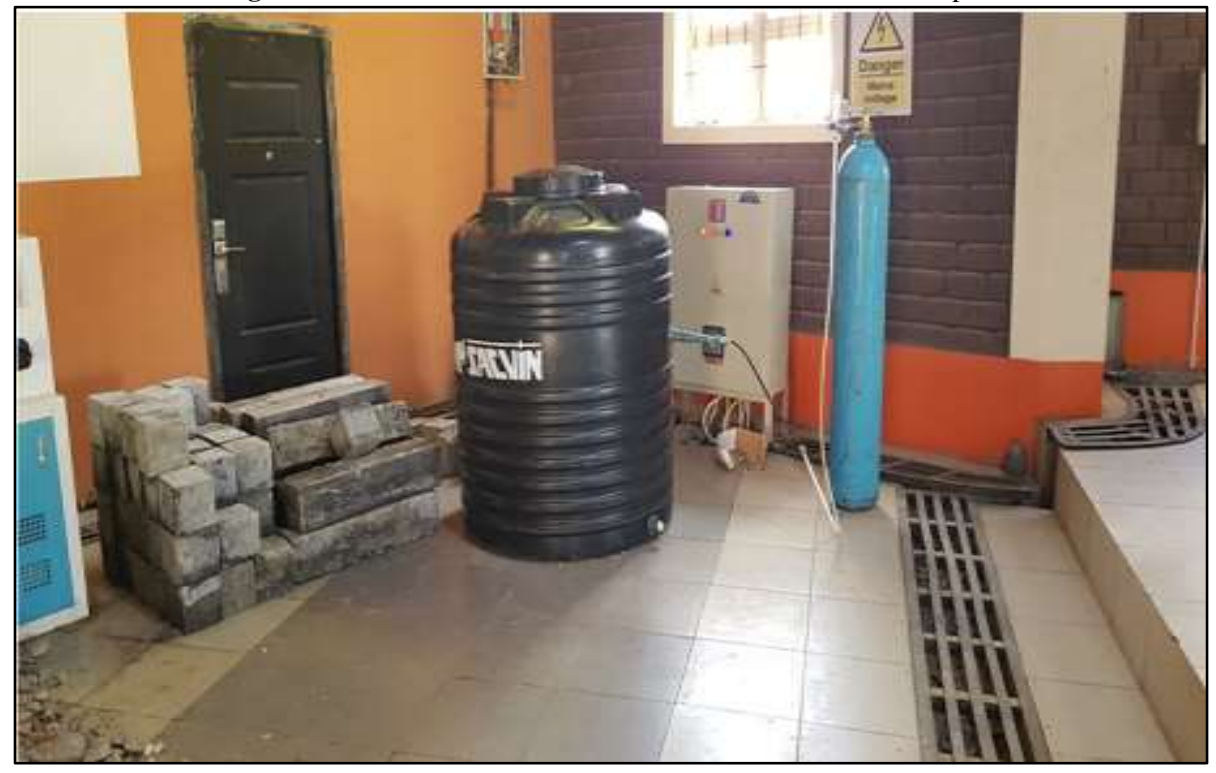

\subsection{Compressive Strength Test}

The compressive strength test was conducted according to BS EN 12390-3 [24]. The concrete cubes were brought out at 7-day, 21-day and 28-day curing periods and tested using compressive strength testing machine. Specimens were loaded to failure in a compression testing machine conforming to BS EN 12390-4 [25]. The maximum loads sustained by the specimens were recorded. The compressive strength of both the carbonated and non-carbonated concrete cubes were obtained and compared at 7-day, 21 days and 28 days.

$$
f_{c}=\frac{F}{A_{c}}
$$

Where

$f_{c}$ is the compressive strength, in megapascals (newtons per square millimeter);

$F$ is the maximum load at failure, in newtons;

$A_{c}$ is the cross-sectional area of the specimen on which the compressive force acts.

\subsection{Weight Loss Test}

The weights of carbonated and non-carbonated cubes were measured at 7-day, 21-day and 28-day curing periods. The weight differences were observed and recorded.

\subsection{Determination of Depth of Carbonation}

The depth of carbonation was measured immediately after performing the weight loss test using phenolphthalein solution. The phenolphthalein indicator solution was prepared by dissolving $0.5 \mathrm{~g}$ of phenolphthalein in $50 \%$ ethanol solution. The concrete cubes were splitted and the surface was sprayed with phenolphthalein indicator solution. The carbonated area remains colorless whereas non-carbonated area changes to purple-red. The depths of carbonation were measured for the various specimen using a vernier caliper.

\subsection{Flexural Strength Test}

Reinforcement cages for the 12 beams were made with $12 \mathrm{~mm}$ reinforcement and with $10 \mathrm{~mm}$ links at $300 \mathrm{~mm}$ spacing as indicated in Figure 2. The flexural strength test was conducted according to BS EN 12390-5 [26] to determine the resistance of the various concrete beam specimens to bending. The maximum loads sustained by the various specimens were determined and the flexural strengths were calculated.

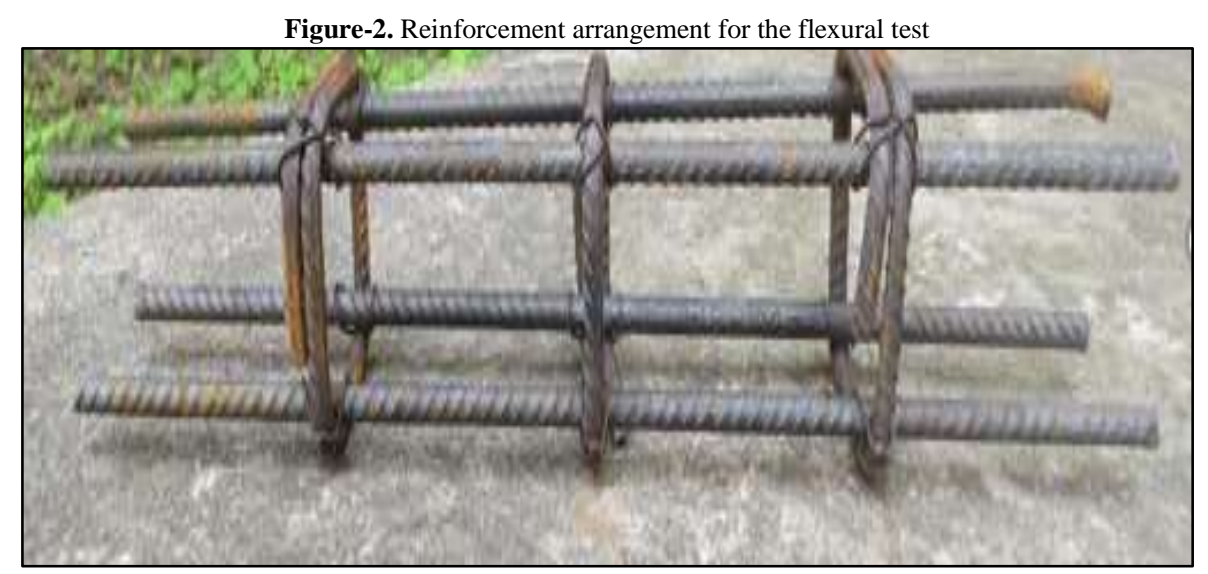


The load was applied on the specimens after proper positioning as shown in Figure 3. A constant rate of stress $0.04 \frac{M P a}{\mathrm{~s}}\left(\frac{\mathrm{N}}{\mathrm{mm}^{2} \mathrm{~s}}\right)$ was used. The load was applied without shock and increase continuously, at the constant rate of $\pm 1 \%$, until failure. The rate of loading on the testing machine was given by Equation 2 while the flexural strengths were obtained using Equation 3.

Where:

$$
R=\frac{s \times d_{1} \times d_{2}^{2}}{l}
$$

$R$ is the required loading rate, in newtons per second;

$s$ is the stress rate, in megapascals per second (newtons per square millimeter per second)

$d_{1}$ and $d_{2}{ }^{2}$ are the lateral dimensions of the specimen, in millimeters

$l$ is the spacing of the lower rollers, in millimeters.

$$
f_{c f}=\frac{F \times l}{d_{1} \times d_{2}^{2}}
$$

Where

$f_{c f}$ is the flexural strength, in megapascals (newtons per square millimeter);

$F$ is the maximum load, in newtons;

$l$ is the distance between the supporting rollers, in millimeters;

$d_{1}$ and $d_{2}{ }^{2}$ are the lateral dimensions of the specimen, in millimeters.

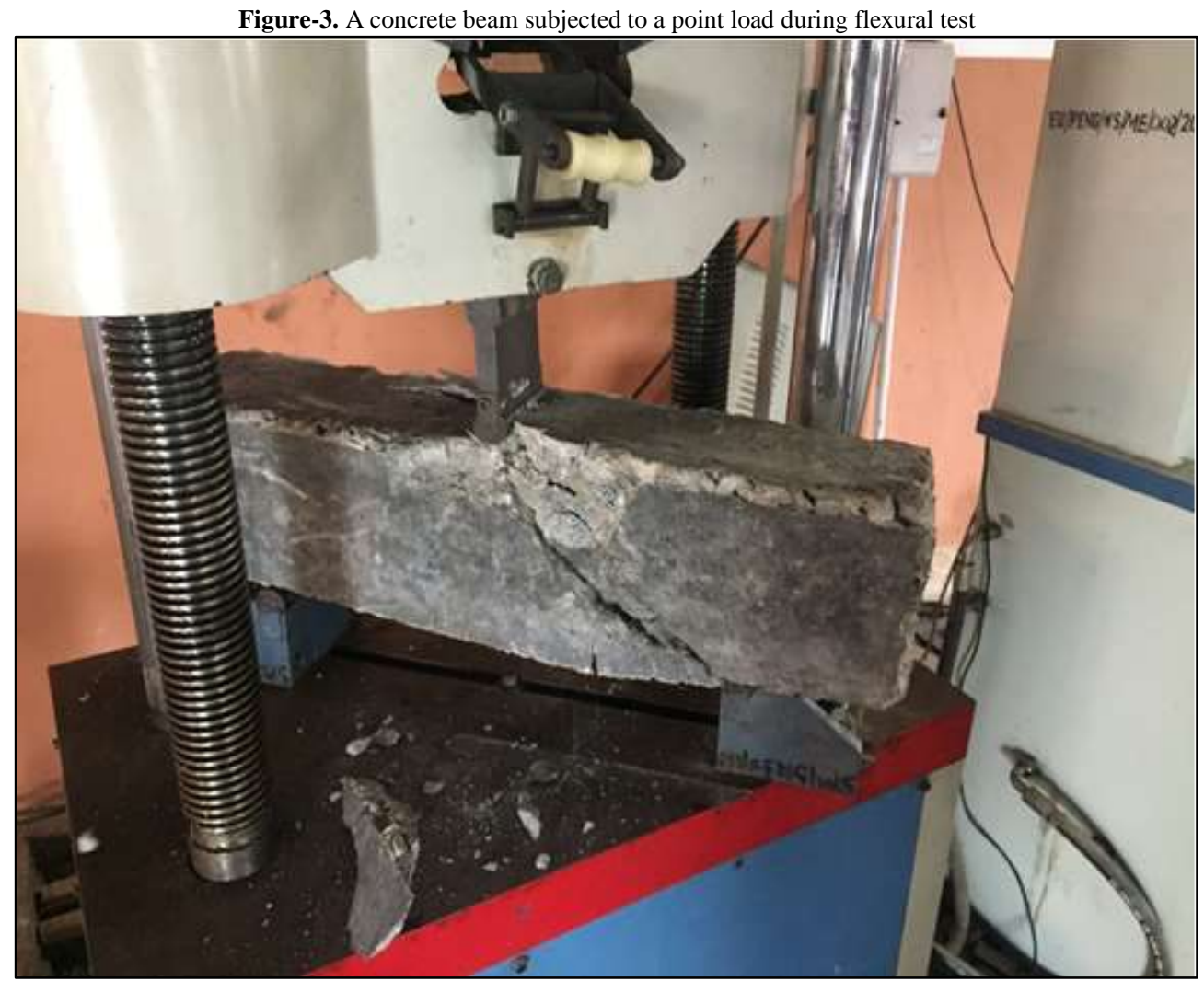

\subsection{Water Absorption Test}

Water absorption test was conducted according to BS 1881-122 [27]. The concrete specimens were dried in the oven for 72 hours. They were weighed and immediately immersed completely in a water tank for $30 \pm 0.5 \mathrm{~min}$. The specimens were shaken to remove the bulk of the water and dried with a cloth as rapidly as possible until all free water was removed from the surface. The specimens were then reweighed afterwards and the percentage water absorption for each of the specimens was calculated using Equation 4.

Percent Water Absorption $=\frac{\text { Wet weight }\left(W_{2}\right)-\text { Dry weight }\left(W_{1}\right)}{\text { Dry weight } W_{1}} \times 100$

\section{Results and Discussion}

\subsection{Results of Materials Properties}

The properties of the research materials were obtained and presented. The Portland lime cement used has a consistency of $34 \mathrm{~mm}$ with $96 \mathrm{~g}$ of water, that is $32 \%$ of $300 \mathrm{~g}$ of cement sample carried out according to BS EN 196-3 [22]. The initial setting time of the cement is $90 \mathrm{~min}$ and final setting time is $543 \mathrm{~min}$. The cement satisfies the requirement in ASTM C191-13 [28] which states that the initial setting time must be greater than 1 hour and final setting should not be greater than 10 hours. The result of the particle size distribution for the fine aggregates is as shown in Figure 4. 
Figure-4. Particle size distribution chart for the fine aggregates

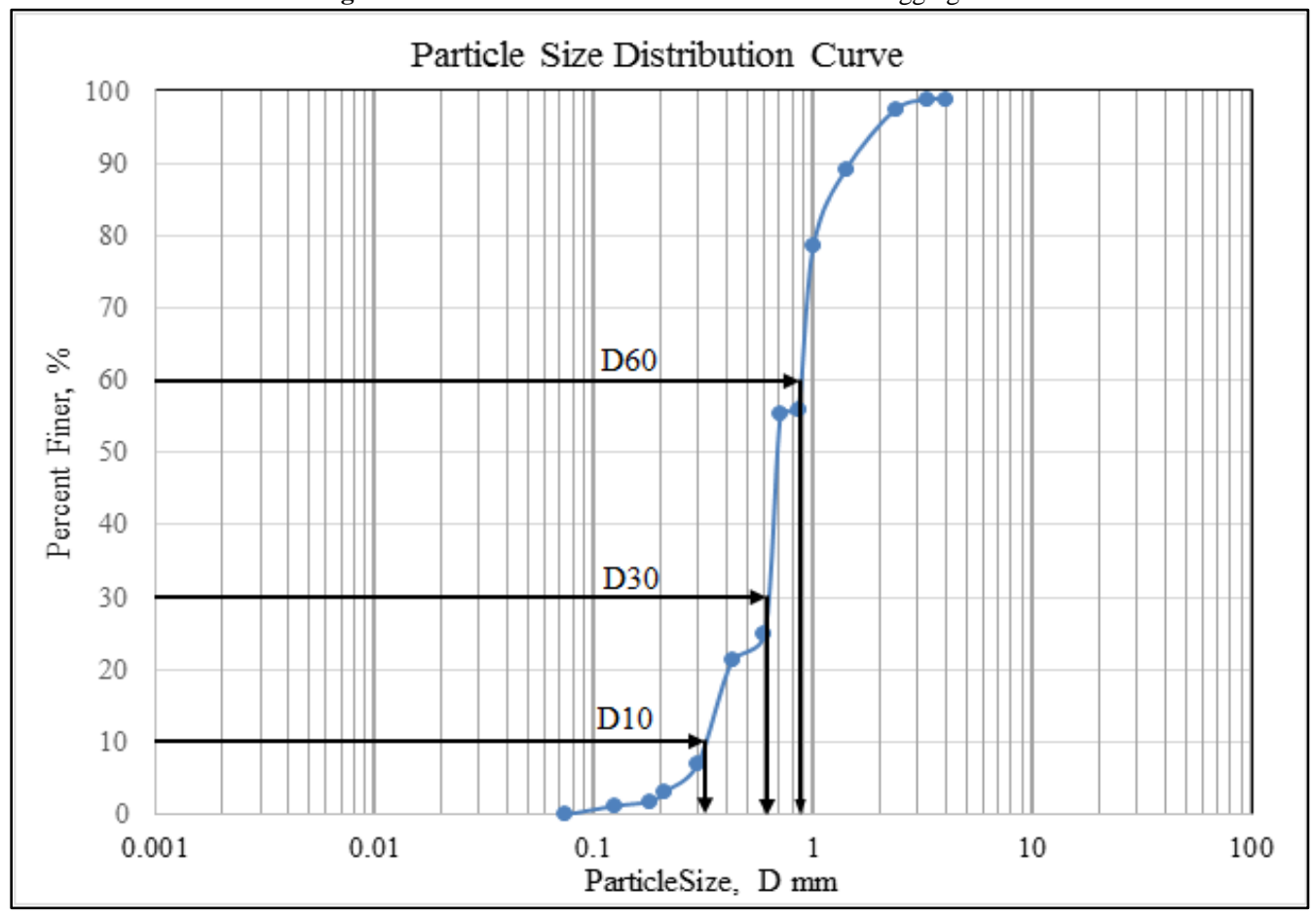

Where

$$
D_{10}=0.324 \mathrm{~mm}
$$

From the particle size distribution in Figure 4, the effective grain size $D_{10}=0.324 \mathrm{~mm}, D_{30}=0.618 \mathrm{~mm}$ and $D_{60}=0.878 \mathrm{~mm}$ which corresponds to 10 percent finer particles, diameter of the particle at 60 percent finer on the grain size distribution curve and the diameter of the particle at 60 per cent finer on the grain size distribution curve respectively. The coefficient of uniformity, $C_{u}=2.708$ and coefficient of curvature, $C_{c}=1.343$. Based on these results the sand can then be classified as well-graded sand of A-1-a group [29].The slump of the fresh concrete was $31 \mathrm{~mm}$ and it can be classified as a true slump.

\subsection{Compressive Strength}

The results of the compressive strengths obtained for both carbonated and non-carbonated concrete samples are presented in Figure 5. The results show the compressive strengths of the carbonated concrete samples to be higher than that of the non-carbonated concrete samples throughout the period of the research. The compressive strength results follow the same trend obtained by the Hussain, et al. [30].

Figure-5. Compressive strength curve

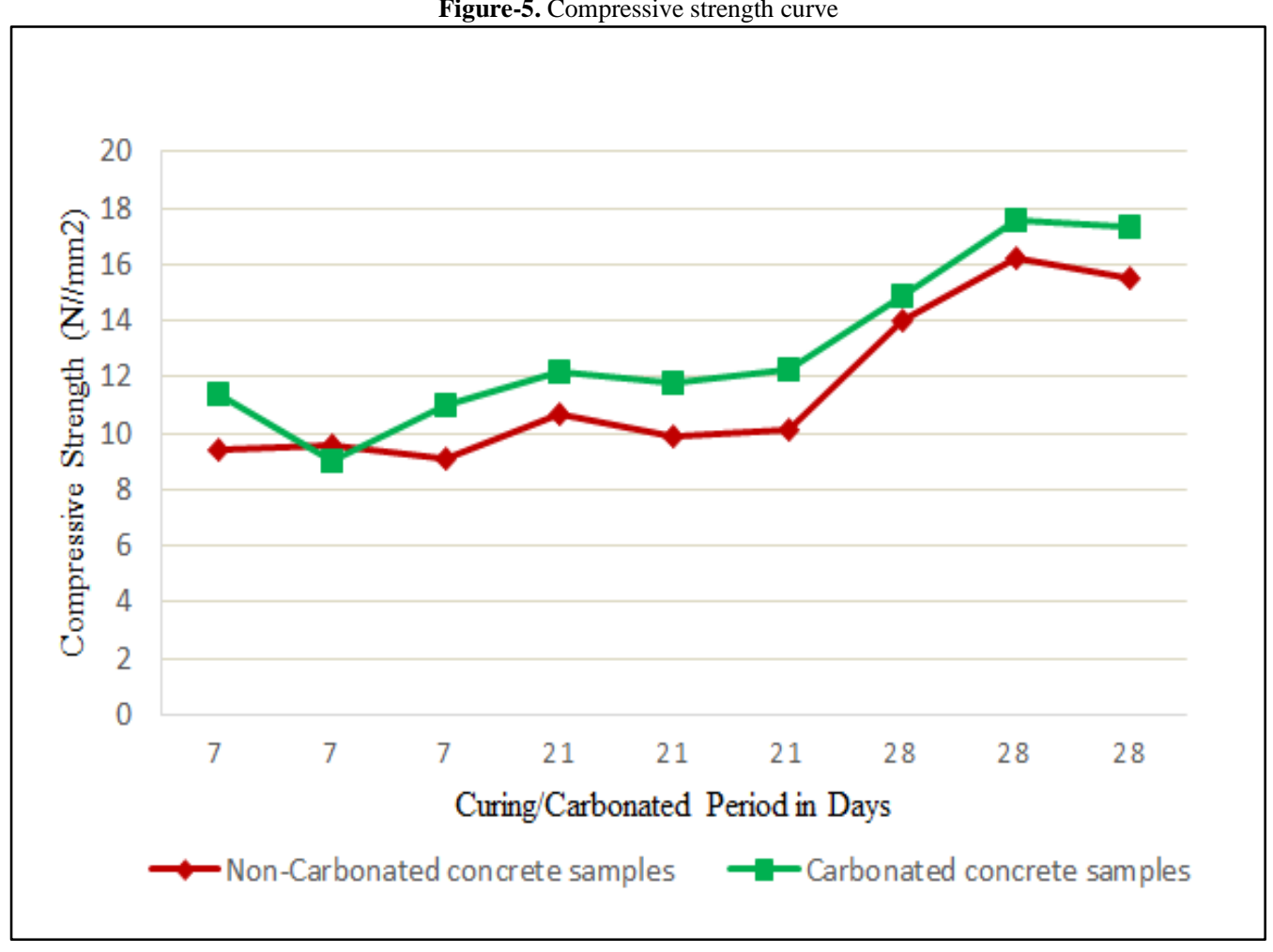




\subsection{Depth of Carbonation}

The results obtained from carbonation test of the concrete samples are shown in Figure 4. The carbonation depth increased with increased in exposure to $\mathrm{CO}_{2}$. Comparing the compressive strength that was obtained at 28 days accelerated carbonation period with the carbonation depth of $2.12 \mathrm{~mm}$ obtained at same carbonated day. It can then be inferred that exposure of concrete to carbonation strengthens the compressive strength of such concrete provided the exposure depth is not more than $2.12 \mathrm{~mm}$ and the nominal cover to such concrete is far greater than $2.12 \mathrm{~mm}$. Previous studies have found that, during the carbonation period, calcium carbonate is produced from the penetration of $\mathrm{CO}_{2}$ in the concrete and since calcium carbonate occupies more space than the calcium hydroxide it is replacing, the resulting concrete will be denser [31].

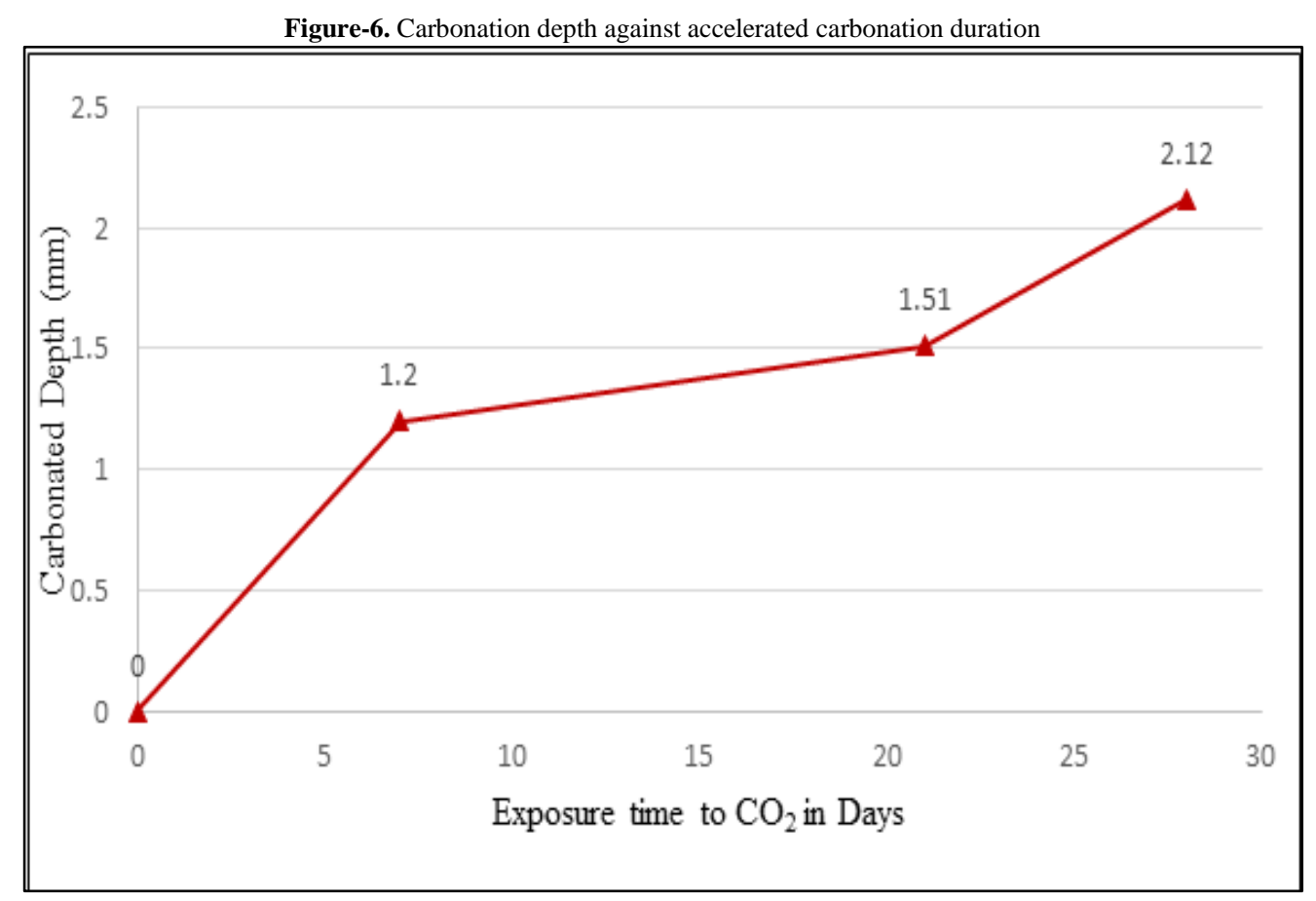

\subsection{Flexural Strength}

Samples of the flexural strength results obtained are shown in Figure 7 and 8 for non-carbonated concrete and carbonated concrete samples respectively. The flexural strength results against the curing/carbonation periods is also shown in Figure 9. There is also an improvement on the flexural strength of the carbonated samples at 28-day curing period. This is in accordance with the result obtained by some past researchers [32]. The formation of calcium carbonate has improved the flexural behavior of the carbonated concrete acting as a thick protective layer of decreased porosity on the concrete surface [31].

Figure-7. Flexural strength for non-carbonated concrete sample 1

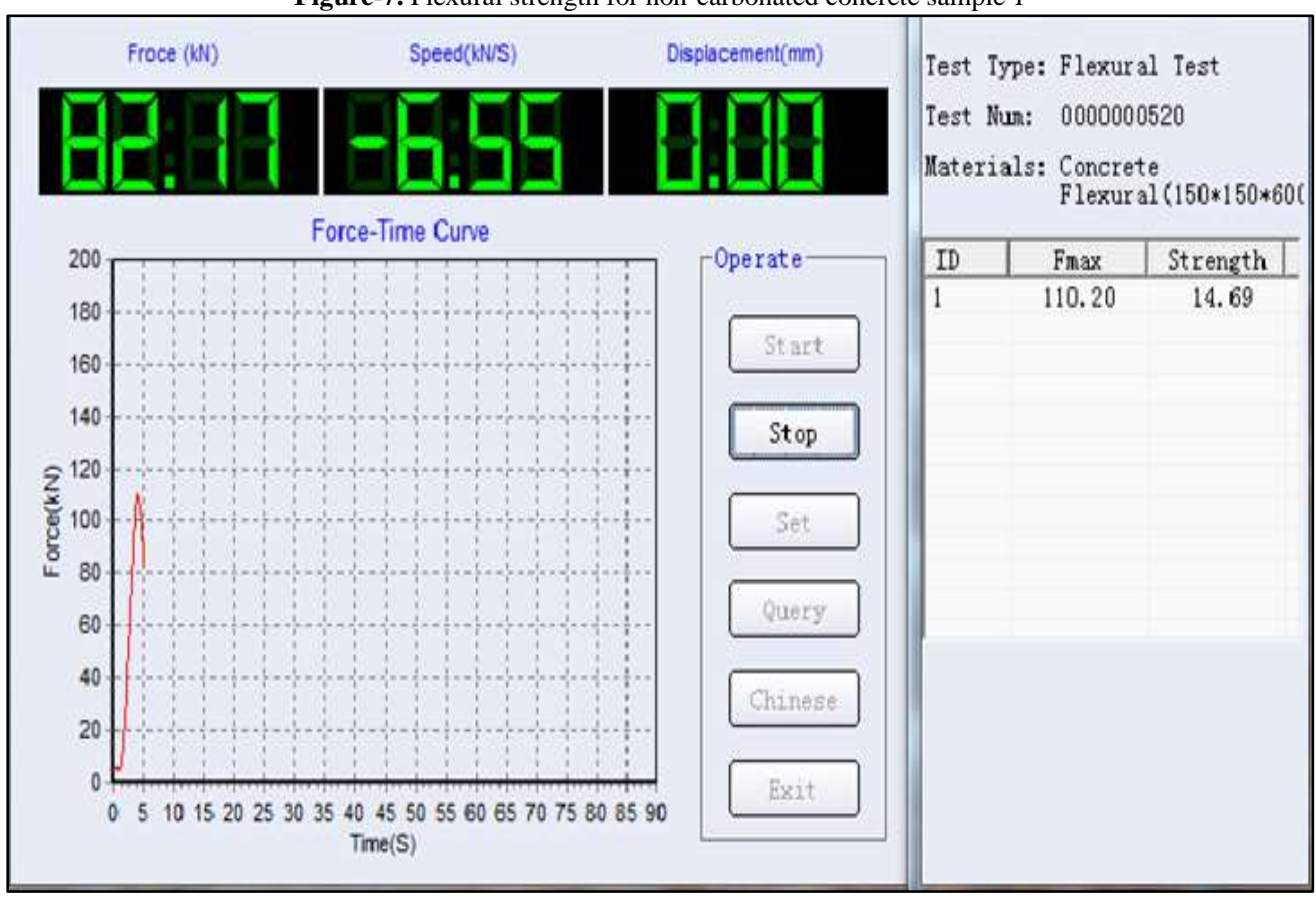


Figure-8. Flexural strength for carbonated concrete sample 1
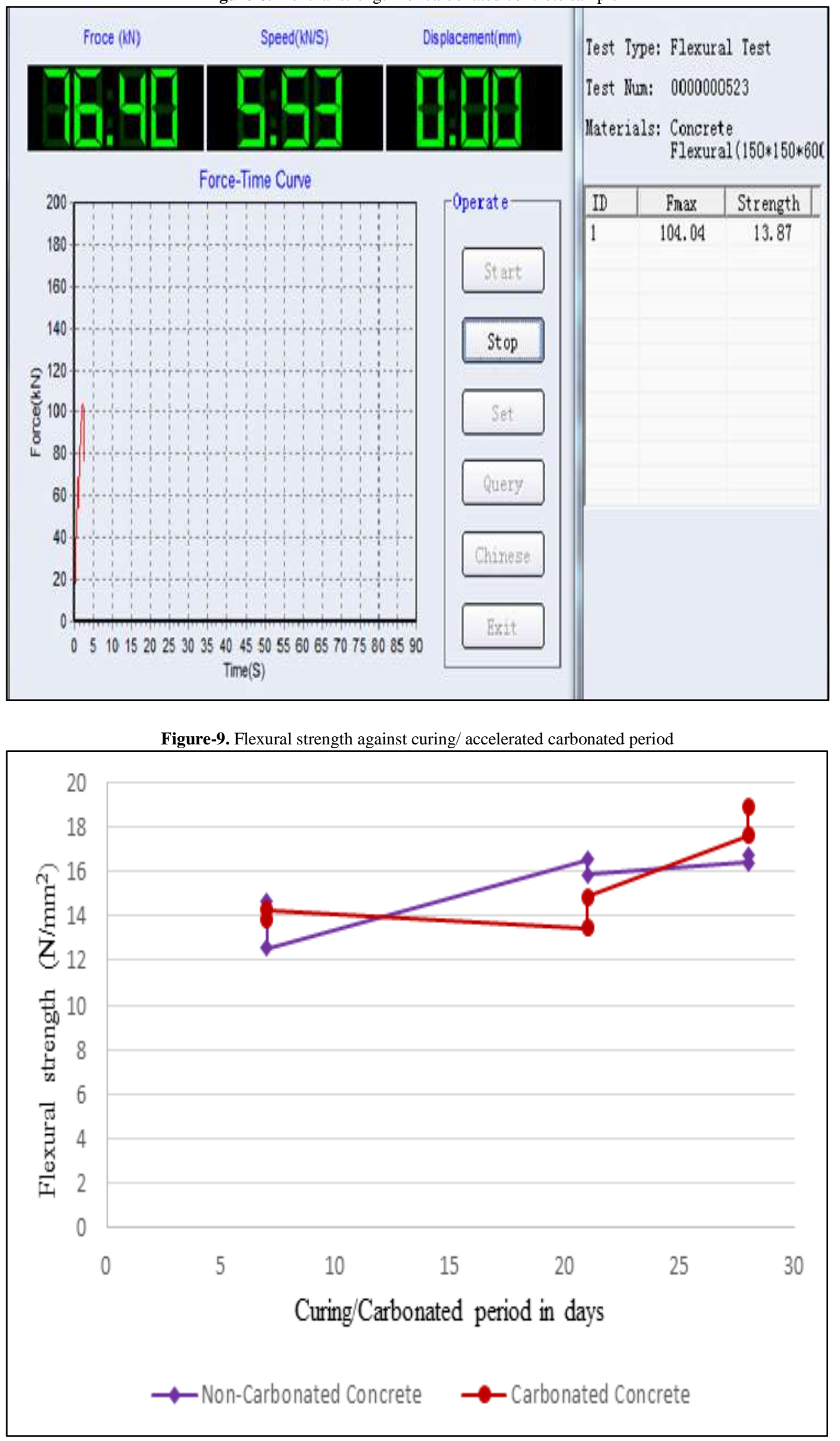

\subsection{Water Absorption}

The change in water absorption rate over the carbonation period is presented in Figure 10. Carbonated concrete shows a decrease in water absorption rate with increase in time while the non-carbonated concrete maintain its water absorption rate even with increase in time. Hussain, et al. [30], reported in the output of their research work that porosity of concrete decreased with increase in duration in the carbonation chamber which also reduce water absorption rate. 
Figure-10. Water absorption against the curing/ accelerated carbonation period

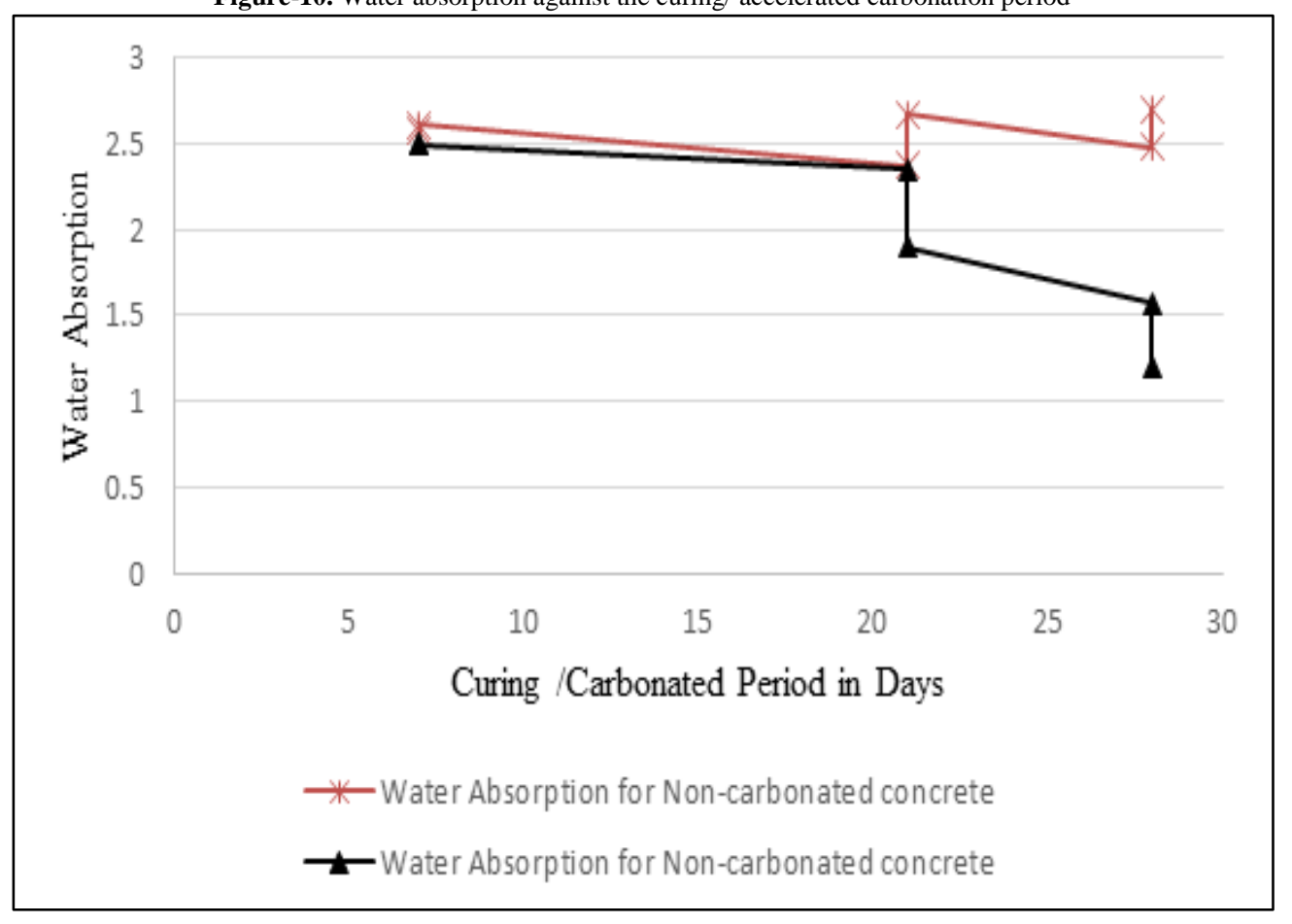

\subsection{Result of the Weight Change}

The results of the changes in weight for the carbonated samples as well as non-carbonated samples are shown in Figure 11. The carbonated concrete specimens showed a slightly higher weight than the non carbonated samples. As the curing/carbonated period increases, the deviation in the weight obtained for either samples decreases. This implies that curing or carbonation stabilizes the weight of concrete.

Figure-11.

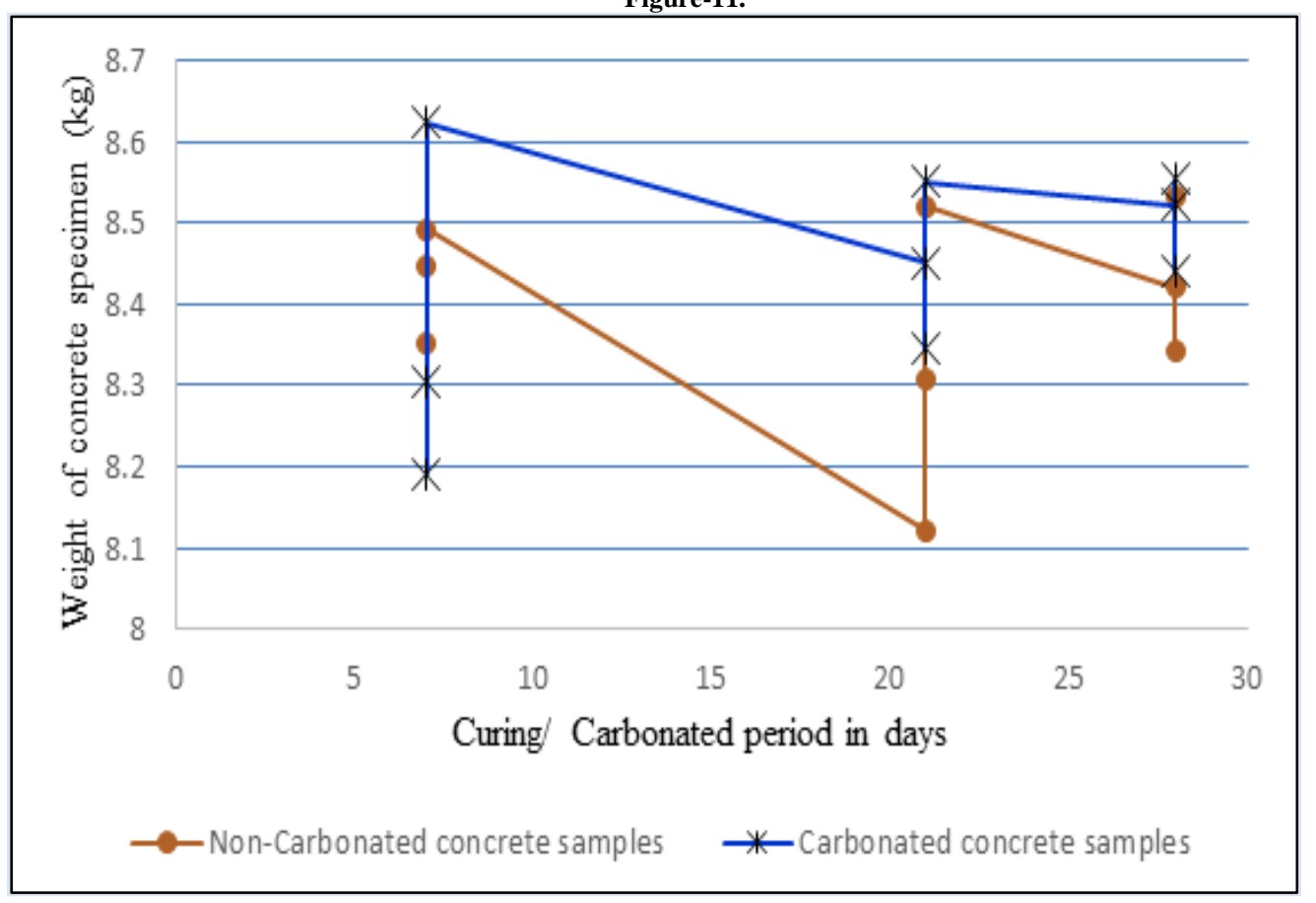

\section{Conclusion and Recommendation}

Within the scope of this research, the following concluding remarks can be made.

(i) Carbonation of concrete improves its compressive strength, therefore precast concrete can be carbonated prior to use. This will reduce the amount of cement needed to achieve the higher compressive strength which carbonation will offer. This will as well consume some quantity of $\mathrm{CO}_{2}$ in our environment thereby reducing global warming and making the environment friendlier.

(ii) Carbonation depth should be adopted as one of the criteria for selecting nominal cover in reinforced concrete, this should be in conjunction with existing criteria. This is to ensure that carbonation does not reach the passive film which offers protection to the reinforcement or the reinforcement level. When 
carbonation reach the passive film of concrete covering the reinforcement or the reinforcement level, corrosion can be initiated which can lead to failure of reinforced structures.

(iii) Carbonation improves other mechanical properties such as flexural strength, water absorption, and weight changes.

\section{References}

[1] Acheampong, 2013. "Comparative study of the physical properties of palm kernel shells concrete and normal weight concrete in Ghana." Journal of Science and Multidisciplinary Research, vol. 5, pp. 129-146.

[2] Hajek, P., 2017. "Concrete structures for sustainability in a changing world." Procedia Engineering, vol. 171, pp. 207-214.

[3] Qasim, O. A., 2018. "Experimental investigation on autogenous shrinkage of high and ultrahigh strength concrete." In IOP Conf. Series: Materials Science and Engineering 454012067.

[4] Qasim, O. A. and Ahmed, A. S., 2018. "Different variable effects on bond strength of normal, high and ultra-high strength concrete." I. J. C. I. E. T., vol. 9, pp. 1923-945.

[5] Woodford, C., 2019. "Concrete and reinforced concrete." Available: https://www.explainthatstuff.com/steelconcrete.html

[6] Gospal, 2018. "The constructor. Retrieved from the constructor." Available: https://theconstructor.org/concrete/\#what is concrete

[7] Almeraya, F., Bastidas, J. M., Acosta, A. A. T., and Tiburcio, C. G., 2012. "Corrosion in reinforced concrete." International Journal of Corrosion, Available: https://doi.org/10.1155/2012/986186

[8] Broomfield, J. P., 2007`. Corrosion of steel in concrete - understanding, investigation and repair. 2 nd ed. London, UK: Taylor and Francis.

[9] Miyazato, S. and Otsuki, N., 2010. "Steel corrosion induced by chloride or carbonation in mortar with bending cracks or joints." Journal of Advanced Concrete Technology, vol. 8, pp. 135-144.

[10] Parrott, L., 1987. "A review of carbonation in reinforced concrete, cement and concrete association report c/1-0987 .Google scholar."

[11] Never, R., Branco, F., and Brito, J., 2013. "Field assessment of the relationship between natural and accelerated concrete carbonation resistance." Cement and Concrete Composite, vol. 41, pp. 9-15.

[12] Rao, V. N. and Meena, T., 2017. "A review on carbonation study in concrete,." In IOP Conf. Series: Materials Science and Engineering. p. 263.

[13] Chi, J. M., Huang, R., and Yang, C. C., 2002. "Effects of carbonation on mechanical properties and durability of concrete using accelerated testing method." Journal of Marine Science and Technology, vol. 10, pp. 14-20.

[14] Papadakis, V. G., Fardis, M. N., and Vayenas, C. G., 1992. "Effect of composition, environmental factors and cementlime motor coating on concrete carbonation." Materials and Structures, vol. 25, pp. 293-304.

[15] Ihekwaba, N. M., Hope, B. B., and Hanaaon, C. M., 1996. "Carbonation and electrochemical chloride." Cement and Concrete Research, vol. 26, pp. 1095-1107.

[16] Neville, M. A., 1995. Properties of concrete. 4th ed. England: Longman Group Limited.

[17] Schiessl, P., 1988. Corrosion of steel in concrete. London: Chapman and Hall.

[18] Veleva, L., Castro, P., Hernandez, G., and Schorr, M., 1998. "The corrosion performance of steel and reinforced concrete in a tropical humid climate. A review." Corrosion Reviews, vol. 16, pp. 235-284.

[19] Chi, J. M. C., Huang, R., and Yang, C. C., 2002. "Effects of carbonation on mechanical properties of concrete." Journal of Marine Science, vol. 10, pp. 14-20.

[20] Concrete Experts, 2006. "Carbonation of concrete. Retrieved from concrete experts international." Available: http://www.concrete-experts.com/pages/carb.htm

[21] BS 1377-2, 1990. Methods of test for soils for civil engineering purposes. Classification tests, British Standard Institution.

[22] BS EN 196-3, 1995. Methods of testing cement. Determination of setting time and soundness. British Standard Institution.

[23] BS EN 12350-2, 2000. Testing fresh concrete. Slump test, british standard institution. British Standard Institution.

[24] BS EN 12390-3, 2009. Testing hardened concrete. Compressive strength of test specimens. British Standard Institution.

[25] BS EN 12390-4, 2019. Testing hardened concrete. Compressive strength. Specification for testing machines. British Standard Institution.

[26] BS EN 12390-5, 2009. Testing hardened concrete. Flexural strength of test specimens. British Standard Institution.

[27] BS 1881-122, 2011. Testing concrete. Method for determination of water absorption. British Standard Institution.

[28] ASTM C191-13, 2014. "Time of setting of hydraulic cement by vicat needle, american society for testing and materials." Available: www.astm.org

[29] AASHTO 145-91, 1993. American association of state and highway transportation officials, recommended practice for the classification of soils and soil-aggregate mixtures for highway construction purposes. Standard Specifications for Transportation Materials and Methods of Sampling and Testing. 
[30] Hussain, S., Bhunia, D., and Singh, S. B., 2016. "An experimental investigation of accelerated carbonation on properties of concrete." Engineering Journal, vol. 20, pp. 1-10.

[31] You, K., Jeong, H., and Hyung, W., 2014. "Effects of accelerated carbonation on physical properties of mortar." Journal of Asian Architecture and Building Engineering, vol. 13, pp. 217-221.

[32] Hussain, S., Bhunia, D., and Singh, S. B., 2016. "An experimental investigation of accelerated carbonation on properties of concrete." Engineering Journal, vol. 20, pp. 1-10. 